\section{Revista Brasileira de Literatura Comparada abralic}

ISSN 0103-6963

e-ISSN 2596-304X
EDITOR-CHEFE:

Gerson Roberto Neumann

EDITOR EXECUTIVO:

Regina Zilberman

SUBMETIDO: 30.04 .2021

ACEITO: 15.06 .2021

\section{COMO CITAR:}

ALÓS, Anselmo Peres.

Transitoriedades, transgeneridades, transidentidades: representação e autoria trans na narrativa brasileira. Revista Brasileira de Literatura Comparada, v. 23, n. 44, p.9-23, set.-dez., 2021. doi: https:// doi.org/10.1590/2596-

304x20212344apa

\title{
Transitoriedades, TRANSGENERIDADES, TRANSIDENTIDADES: REPRESENTAÇÃO E \\ AUTORIA TRANS NA NARRATIVA BRASILEIRA
}

\author{
Transitoriness, transgenerities, transidentities: representation \\ and trans authorship in Brazilian narrative
}

\begin{abstract}
Anselmo Peres Alós 1
${ }^{1}$ Universidade Federal de Santa Maria. Santa Maria, RS, Brasil.

E-mail: anselmoperesalos@gmail.com

\section{RESUMO}

O objetivo desse artigo é a construção de um itinerário que diz respeito a duas questões. Por um lado, mapeia-se a tradição da representação de personagens transgêneros - especialmente protagonistas - na narrativa brasileira escrita por autores transgêneros; por outro, discute-se a emergência do fenômeno que pode ser chamado de autoria transgênero no campo da narrativa contemporânea brasileira, dando-se especial atenção aos livros escritos por João Nery (Erro de pessoa, de 1985, e Viagem solitária, de 2011) e Loris Ádreon (Meu corpo, minha prisão, de 1985). Finalmente, são apresentadas algumas considerações em torno de recorrências tropológicas ao longo dessas três narrativas.
\end{abstract}

PALAVRAS-CHAVE: transidentidades; autoria transexual; personagens transgêneros.

\begin{abstract}
The aim of this paper is to construct an itinerary when it comes to two questions. On the one hand, the tradition of representation of transgender characters - especially main characters - in Brazilian narrative written by cisgender authors is presented; on the other hand, the emergence of the phenomenon that we can call transgender authorship in the field of contemporary Brazilian narrative is mapped, giving special attention to the books written by (Erro de pessoa, first published in 1985, e Viagem solitária, first published in 2011)) e Loris Ádreon (Meu corpo, minha prisão, first published in 1985). Finally, some considerations around tropological recurrencies along these texts are discussed.
\end{abstract}

KEYWORDS: transidentities; transexual authorship; transgender characters.

http:// www.scielo.br/rblc

https: //revista.abralic.org.br 


\section{PREÂMBULO}

Ela tem cara de mulher, ela tem corpo de mulher Ela tem jeito, tem bunda, tem peito e o pau de mulher

Ela é amapô de carne osso, silicone industrial Navalha na boca, calcinha de fio dental

Navalha, navalha, valha Navalha, navalha, valha

Navalha na boca E calcinha de fio dental (Linn da Quebrada, "Mulher") ${ }^{1}$

N os últimos 20 anos, a visibilidade alcançada por pessoas trans na cultura popular e na mídia tem colaborado muito para ampliar o alcance dos debates dos movimentos travesti, transexual e transgênero. O reality show estadunidense RuPaul's Drag Race (2009-presente) provavelmente seja o mais popular artefato cultural contemporâneo nesse sentido, embora possamos elencar também a quinta edição do Big Brother UK (2004), cuja vencedora foi Nadia Almada, uma mulher trans de ascendência portuguesa de 27 anos. No campo das produções cinematográficas e televisivas, emerge e ganha visibilidade uma importante geração de atores e atrizes trans desempenhando papéis importantes - não raro de protagonistas - tais como Daniela Vega (Uma mujer fantástica, Chile, 2017), Mya Taylor e Kitana Kiki Rodríguez (Tangerine, Estados Unidos, 2015), Harmony Santana (Gun Hill Road, Estados Unidos, 2011), Alexandra Billings, Trace Lysette e Ian Harv (que atuaram na série estadunidense Transparent, lançada em 2014), Laverne Cox (que participou de Orange is The New Black, série estadunidense lançada em 2013), Tarso Brant (ator brasileiro que participou de $A$ força do querer, telenovela produzida pela Rede Globo em 2017), Indya Moore e MJ Rodriguez (Saturday Church, filme estadunidense de 2017) ${ }^{2}$. No cenário recente dos influenciadores digitais, os YouTubers, merecem destaques em canais mantidos e apresentados por pessoas trans, tais como Mandy Candy, Thiessa, Lucca Najar, Rosa Luz, Xisto Marina, Peter The Pan, Hugo Nasck e Ariel Modara, apenas para falar de digital influencers brasileiros. No cenário musical brasileiro recente, merecem destaque nomes como os de Liniker, Potiguara Bardo, Jup do Bairro, Linn da Quebrada, Raquel Virgínia, Assucena Assucena, Mel Gonçalves, Pepita, Majur, Monna Brutal, Alice Marcone, Bixarte, Bombeat, Julian Santos e Oxa, emergindo mais ou menos simultaneamente ao fenômeno pop Pablo Vittar.

1 "Mulher" é uma composição de Linn da Quebrada, parte integrante do EP Pajubá, de 2017. Letra disponível em <https://www.letras. mus.br/mc-linn-da-quebrada/mulher/>; faixa de áudio do EP disponível em <https://youtu.be/V8UxhqxA_Ms?list=OLAK5uy_ nobNtjQAXSCTQpSYINbJLGU2Qc2vHz_5w>. Acesso: 16 de abril de 2021.

2 Cabe ainda mencionar a série televisiva Pose, produzida pela FX, série televisiva dramática sobre o cenário queer de New York entre os anos 1980 e 1990, dando particular destaque para a comunidade queer trans afro-estadunidense e latina. Criada por Ryan Murphy, Brad Falchuk e Steven Canals, a série estreou em 2018 nos Estados Unidos. No casting da série, que exibe o maior elenco de mulheres transexuais já escalonado para uma série televisiva de ficção, estão MJ Rodriguez, Dominique Jackson, Indya Moore, Hailie Sahar, Angelica Ross, todas pertencentes ao elenco fixo, ademais de participações pontuais de outras atrizes transexuais, tais como Bianca Castro (também conhecida como Jiggly Caliente, nome drag que usava antes de completar sua transição), e Miss Peppermint. A primeira temporada foi aclamada pela crítica com inúmeras premiações, incluindo o Globo de Ouro de Melhor Série Dramática e o Globo de Ouro de Melhor Ator em Série Dramática (recebido por Billy Porter). A primeira temporada foi ao ar ao longo de 2018, e a segunda, ao longo de 2019. A terceira temporada estreou em dois de maio de 2021, com um delay temporal considerável, provocado pelas dificuldades em se prosseguir com as gravações em função da pandemia de COVID-19 que assola o planeta desde 2020. 
Mesmo sendo verdade que alguns autores continuem insistindo em uma narrativa-mestra para a questão das transidentidades centrada quase que exclusivamente na questão da transexualidade e da disforia de gênero (Cf. PROSSER, 1998), começam a emergir no contexto acadêmico uma série de trabalhos que se propõem a redefinir a questão da transgeneridade em um sentido mais amplo, opondo-se às regras tácitas e frequentemente pouco questionadas da heteronormatividade e da cisnormatividade, de modo a problematizar e colocar em xeque a própria questão das matrizes taxonômicas de enquadramento epistêmico do gênero e da sexualidade (Cf.BORNSTEIN, 1994 e HALBERSTAM, 1998 e 2005). Qual a amplitude do termo guarda-chuva "transgênero" e de seu correlativo "transgeneridade" (que, pela utilização do sufixo -dade, pressupõe o campo semântico de condição)? Para Sally Hines, a categoria transgênero relaciona-se com uma ampla gama de práticas que colocam em questão os regimes tidos como normativos de sexo, gênero e sexualidade. Práticas, vivências e existências relacionadas ao travestismo, à transexualidade, à intersexualidade, às construções não binárias de gênero, à fluidez de gênero e à performatividade drag queen não raro são elencadas sob o termo, não sem disputas, resistências e objeções. Se, por um lado, essa compreensão ampla da noção coloca o campo da transgeneridade e das transidentidades quase que superposta ao campo epistêmico de interesses dos estudos e da teoria queer (Cf. ALÓS, 2020), por outro lado essa amplitude na compreensão do termo salvaguarda a discussão da tentação neocartesiana de sistematização, definição e classificação que, não raro, termina por gerar regimes de normalização, de regulação e de hierarquização. Para os fins da discussão que aqui se apresenta, toma-se o termo no mesmo sentido mobilizado por Sally Hines:

[...] 'transgender' is used as an umbrella term to cover a diversity of practices that envolve embodied movements across, between, or beyond the binary categories of male and female. My use of the term 'transgender' thus relates to transsexual identities and practices, and those that are articulated from a variety of other (trans)gender positions. (HINES, 2007, p. 1)

A comunidade trans (e sua respectiva presença nas arenas do debate teórico-crítico) ganhou significativo relevo e importância a partir do início da década de 1990, particularmente dentro do contexto da teoria queer e das discussões pós-modernas e/ou pós-estruturalistas em torno de tópicos do feminismo, dos estudos de gênero e das discussões sobre sexualidade (particularmente das sexualidades dissidentes, isto é, aquelas não centradas na heteronormatividade). Particularmente no contexto existencial das pessoas que desejam realizar a transição de um gênero a outro através da cirurgia de redesignação sexual, a questão do reconhecimento da condição sexual passa por uma patologização ligada a diagnóstico médico - nomeadamente designada de Transtorno de Identidade de Gênero, no DSM-IV, revisada e descrita como disforia de gênero a partir do DSM- $V$. A premissa que ser transexual ou transgênero não envolve uma desordem médica ou mental ${ }^{3}$ foi um passo fundamental para a construção, tanto no seio dos coletivos e do movimento social quanto dentro da universidade, para a consolidação do pensamento trans e da construção da sua (ainda que incipiente e quase embrionária) legitimidade dentro da academia.

\footnotetext{
3 O DSM (Diagnostic and Statistical Manual of Mental Disorders [Manual Diagnóstico e Estatístico de Transtornos Mentais]) é uma publicação da American Psychiatric Association que descreve e cataloga os distúrbios de saúde mental, que teve publicada sua quarta edição (DSM-IV) em 1994, e sua quinta edição (DSM-V, a edição corrente) em 2013. Uma das grandes questões levantadas em alguns setores do movimento trans é o fato de que se, por um lado, a possibilidade de acesso à cirurgia de redesignação sexual é um grande avanço e possibilita a diminuição do sofrimento psíquico das pessoas trans, por outro, o acesso a cirurgia, na maioria dos países (como é o caso do Brasil) só é liberada e aprovada após dois anos de acompanhamento psiquiátrico da pessoa trans em questão, que precisa ter averiguada e diagnosticada sua condição de transgeneridade/transexualidade a partir de um laudo médico que a coloca na condição de objeto do discurso biomédico. Conferir, a esse respeito, BENEDETTI (2005), BENTO (2006), BORBA (2016), BRASIL (2010), BRASIL (2013), ROCON et alli (2016), ROCON (2018).
} 
O pensamento trans tem colaborado sobremaneira para questionar e fertilizar os debates no campo do discurso biomédico e da saúde mental (especialmente a luta pela despatologização das identidades trans no campo da psiquiatria), mas também na teoria gay e lésbica, nos feminismos e na teoria queer. $\mathrm{O}$ pensamento trans simultaneamente avalia e questiona as forças e as limitações desses modelos teóricos com relação às práticas, vivências e (r)existências corporificadas no cotidiano de pessoas trans.

As perspectivas biomédicas no que diz respeito à questão trans historicamente ocupam uma posição dominante que vem afetando significativamente as modalidades através das quais a transgeneridade vem sendo vista, estudada e mesmo vivenciada na contemporaneidade ocidental. Se é verdade que os discursos médicos contemporâneos têm produzido interessantes concepções acerca da transgeneridade e da transexualidade, bastante diferentes das posições mais ortodoxas e patologizantes que predominaram no campo ao longo do século XX, também é verdade que se mantêm no campo das ciências e das práticas biomédicas - e com muito mais força que eu gostaria de admitir - posturas profundamente patologizantes, quando não moralizantes (e do tipo de moralismo para o qual não há espaço no campo da ciência) em torno da transgeneridade.

Algumas questões merecem destaque para que se compreenda o debate em torno da questão trans no campo mais específico dos estudos literários e culturais. Primeiramente, como a transgeneridade e a transexualidade emergem como um tema de interesse social e cultural? Em seguida, como a teoria social, os estudos culturais e o feminismo têm tratado a questão trans? E, finalmente, que tipos de relações e alianças podem ser desenvolvidas entre os sujeitos trans e as teorias/políticas dos movimentos sociais que se construíram em torno de agendas tais como o gênero, a sexualidade e a intimidade, bem como em torno de pautas que lutam pela cidadania e pelo reconhecimento?

O debate interno desse campo epistêmico emergente - que, na academia anglófona, atende pelo nome de transgender studies (estudos transgêneros) - preocupa-se, fundamentalmente, com a questão de como as identidades de sexo/gênero são construídas e, por extensão, são passíveis de serem desconstruídas e reconstruídas no seis das investigações contemporâneas sobre gênero, sexualidade e identidade sexual, não raro com um robusto diálogo - nem sempre sem confrontos e disputas - com o campo dos estudos e teorias feministas. Isso é de profunda e significativa importância para questões sociais mais amplas, tais como as de corporificação, reconhecimento na esfera pública, identidade coletiva e identidade pessoal/subjetiva, tal como sugere Sally Hines:

Transgender raises questions about the formation of identity, and the extent to which we can shape and reshape individual and collective identities. These matters are central to contemporary debates around gender, sexual and intimate identities and the materiality of the body. (HINES, 2007, p. 3)

\section{PRESENÇA TRANS NO CAMPO LITERÁRIO BRASILEIRO: OBJETOS DA REPRESENTAÇÃO}

É bem verdade que a presença de travestis, transexuais e transgêneros como objetos da representação possuem uma história relativamente longa na literatura brasileira, que remonta ao início do século XX. Podemos pensar em Diadorim, o/a jagunço/a e companheiro/a de Riobaldo do clássico Grande sertão: veredas (1956), de João Guimarães Rosa, ou em Timóteo, recluso que vive trancafiado em um dos quartos, vestido com as roupas da tia-avó Maria Sinhá, e se tornou célebre em função do lugar ocupado por de Crônica da casa assassinada (1959), de Lúcio Cardoso, na historiografia literária brasileira. Diadorim e 
Timóteo, mesmo ocupando um lugar relevante e significativo na memória literária brasileira em função da legitimidade que lhes é dada pelo fato de figurarem em obras inquestionavelmente consideradas canônicas e modelares da literatura brasileira, sintomaticamente ocupam lugares de coadjuvantes nas respectivas narrativas às quais pertencem. O escritor sul-rio-grandense Caio Fernando Abreu também abriu espaço para alguns personagens trans em sua obra - na maioria das vezes, como personagens satélite, secundárias na construção de seus enredos. Um de seus contos merece particular destaque nesse sentido. "Sargento Garcia”, conto integrante do livro Morangos mofados, publicado em 1882, traz a personagem Isadora, administradora de uma garçonnière na cidade de Porto Alegre. Em outra ocasião, já discuti a aparição dessa personagem no conto, bem como o fato de sua provável inspiração ter sido Luiza Felpuda, personagem da história underground de Porto Alegre nos tempos da ditadura civil-militar a quem o escritor dedica o conto:

Caio Fernando Abreu dedica este conto à memória de Luiza Felpuda, famosa travesti de Porto Alegre que, entre 1960 e 1980, mantinha um bordel muito frequentado por militares, localizado nas cercanias do bairro Menino Deus. A personagem Isadora é, também, um tributo realizado pelo autor à memória de Luíza Felpuda, que morreu sob condições suspeitas em um atentado a bomba no início da década de 1980, tal como Paulo Heuser rememora na crônica "A rua"4. (ALÓS, 2019, p. 105)

Todavia, quando o leitor se livra dos grilhões normativos do cânone e dos textos consagrados, é possível encontrar sujeitos trans encarnando protagonistas. A primeira protagonista travesti em uma narrativa brasileira, independentemente do gênero literário em questão, aparece no conto "A grande atração", de Raimundo Magalhães Jr., publicado pela primeira vez em 1936 (trata-se da personagem Luigi Bianchi). Já a primeira travesti a figurar como protagonista em um romance, até onde pude rastrear, é Georgette, do romance homônimo, publicado em 1956, por Cassandra Rios. Finalmente, a terceira travesti protagonista em uma narrativa (e a segunda em um romance) seria a personagem Ana Maria, do romance Uma mulher diferente, também de Cassandra Rios, publicado pela primeira vez em 1965. Em 1966, Walmir Ayala publica o conto “Taís”, que traz ao leitor um protagonista anônimo que, desde os primórdios de sua infância, deseja vestir-se de mulher. Quando adulto, é apelidado de Taís, e esse é o único nome que lhe é atribuído ao longo do conto; ao final da narrativa, tem de resignar-se e abrir mão de seus desejos de vestir-se como uma mulher.

A partir da década de 1970 há um sensível crescimento na aparição de personagens travestis retratadas na ficção brasileira. Adelaide Carraro, escritora conhecida como pornográfica e folhetinesca, e que justamente por isso enfrentou problemas com as patrulhas moralistas da ditadura civil-militar pós- $1964^{5}$ publicou, em 1970, o romance $O$ travesti, que narra a trajetória de Rubens de Moraes Barros

\footnotetext{
4 "Eis que eu estava participando de um curso no Rio, quando meus colegas cariocas comentaram que havia ocorrido um atentado em Porto Alegre. Sem internet, só consegui notícias através dos jornais impressos. Após vasculhar alguns, encontrei a tão procurada notícia. Seria um atentado contra a $\mathrm{OAB}$ ? Ou o alvo seria a imprensa? Nem um, nem outro. Ocorrera uma explosão na minha tão familiar Rua Caldas Júnior, quase na esquina com a [Rua] Riachuelo. Parecia obra de uma brigada moralista, pois o alvo fora uma casa de costumes, como se dizia na época. Lembro-me dela, por fora, bem entendido. Subitamente, no meio da madrugada, uma imensa explosão lançou pela janela o cidadão, cujo nome não lembro, cuja alcunha não esqueço. Pois o vivente usava o codinome Luísa Felpuda. Não havia como esquecê-lo, não é? Luísa Felpuda alçara voo, estatelando-se no meio da Caldas Júnior. Assim como a funcionária Lydia Monteiro da Silva, da OAB do Rio, Luísa Felpuda, da Caldas Júnior, morreu. Involuntários personagens de eventos isolados de explosões, que tiveram o mesmo fim”. Disponível em: <http://pauloheuser. blogspot.com/2006/12/rua.html>. Acesso em: 02 de setembro de 2018.

5 Com relação às conturbadas relações de Adelaide Carraro e sua extensa produção romanesca ao longo dos anos da ditadura civil-militar brasileira, conferir REIMAO (2014) e LARANGEIRA (2016).
} 
e seu processo de transição até se tornar Jaqueline, uma travesti que se prostitui nas ruas de São Paulo. Carraro retrata nessa narrativa questões tais como o processo de mudança do corpo, as discriminações sociais, e as perseguições policiais sofridas pelo protagonista tanto em seu processo de transição quanto eu sua tentativa de resistência como sujeito que se constitui performativamente no feminino ao assumir uma identidade travesti.

O conto "Dia dos Namorados" (1975), de Ruben Fonseca, também associa a prostituição à figura da travesti. A personagem central da narrativa, Viveca, é uma travesti mitomaníaca e ladra, que chantageia o banqueiro J. J. Santos, na tentativa de o extorquir. A personagem é construída através dos tradicionais filtros estereotipados que associam as travestis ao crime, à prostituição e ao estelionato. "Ruiva" é o título do conto de Julio César Moreira Martins, publicado em 1978 na antologia Sabe quem dançou?. O conto narra os eventos através da visão do protagonista Juarez Moreira, relojoeiro mineiro que se muda para São Paulo com o objetivo de realizar a sua transição de identidade de gênero e viver como Gina, uma travesti ruiva em busca de amor, romance e liberdade pelas ruas da capital paulista. Gina, afastada de sua cidade natal e decepcionada com a realidade da cidade grande, termina por voltar para o interior de Minas Gerais.

O script narrativo dos contos de Julio César Moreira Martins e de Ruben Fonseca assemelhase, em muitos aspectos, às narrativas que Roberto Freire publica em 1978, no volume intitulado Travesti. O livro é constituído por duas novelas que se dedicam a retratar trajetórias de pessoas trans, intituladas "O milagre" e "A cortada". Nas duas novelas, a ênfase recai na experiência de exílio psíquico e de abandono familiar sofrida pelas protagonistas. No ano seguinte, surge o romance de autoria de Leopoldo Serran, publicado pela Codecri (editora afiliada e mantida pelo grupo de intelectuais que estava arregimentada no entorno de $O$ Pasquim). No romance de Serran, a beleza, a sensualidade e a voluptuosidade são as marcas da construção da personagem cujo nome dá título ao romance, Shirley. Como nas demais narrativas até aqui mencionadas, a construção do enredo em torno da protagonista uma vez mais valoriza as mudanças corporais e a transição do gênero masculino para o gênero feminino.

Publicado em 1999, o romance Nicola, de Danilo Angrimani, foi editado pelas Edições GLS - grupo editorial que surge em meados da década de 1990 com o intuito de promover uma imagem positiva e higiênica para com a sexualidade excêntrica. O protagonista é um professor universitário, casado e com filhos, com um alter ego feminino que deseja vestir-se e comportar-se como mulher. A narrativa peca pelo bom-mocismo e por um certo discurso quase higienista que defende a assimilação, indo de encontro aos pilares das obras de ficção publicadas ao longo da década de 1990, que não levava à estampa histórias nas quais houvesse apologia às drogas, imagens estereotipadas ou consideradas "negativas" da comunidade LGBTQIA+. Isso fica expresso no próprio anúncio do livro do website da editora, que destaca, na narrativa, um explícito moralismo de índole quase higienista e um certo repúdio ao "mau gosto":

Um professor universitário sisudo, casado e com filhos, tem uma vida secreta: quando se olha no espelho, vê uma mulher vagabunda e aventureira esperando para se manifestar. Primeiro romance brasileiro a explorar a fluidez de gêneros, Nicola acompanha um personagem que se traveste com uma linguagem vigorosa, honesta e sem qualquer vulgaridade ${ }^{6}$. [grifos meus]

Apesar de relativamente longa, essa lista de personagens trans na narrativa brasileira não é - e nem se pretende - exaustiva, completa ou definitiva. Todavia ela se faz necessária, inclusive como um

6 Nicola. Disponível em: <https://www.gruposummus.com.br/livro/nicola/>. Acesso em: 16 de abril de 2021. 
gesto de repúdio à amnésia que frequentemente grassa no campo do trabalho crítico envolvendo o mercado editorial, e mesmo os estudos literários. Incomoda o destaque dado pelo website da editora à "linguagem vigorosa, honesta e sem qualquer vulgaridade"? Seguramente sim, já que o juízo de valor que vê a vulgaridade como negativa ou destituída de valor reflete um julgamento caduco quando ao funcionamento da linguagem na literatura de ficção, ignorando uma longa tradição da "vulgaridade" e da libertinagem na literatura ocidental que remonta a Catulo, às cantigas de escárnio e de maldizer do cancioneiro medieval galaico-português, e ao "mau-gosto" de Donatien Alphonse François de Sade, Leopold Von Sacher-Masoch e Pauline Réage, ou à lírica anárquica, satírica e pornô-escatológica de Glauco Mattoso. Todavia, o que mais incomoda é a escandalosa afirmação - provavelmente estratégia de marketing - de qualificar o romance como "o primeiro romance brasileiro a explorar a fluidez de gênero", ignorando toda uma tradição literária com nomes como os anteriormente mencionados: Cassandra Rios, Adelaide Carraro e Leopoldo Serran.

\section{“O QUE ACONTECE QUANDO O OBJETO COMEÇA A FALAR?”}

Tomo de assalto e me aproprio, aqui, do título utilizado por Rita Terezinha Schmidt em artigo publicado em 1999 sobre a ficção de Zora Nearle Huston. É sintomático observar que, em todas as narrativas elencadas na seção anterior, os autores e autoras que se ocuparam de narrar as vidas transexuais, travestis e transgêneras são cissexuais. Mesmo nos casos de escritoras mulheres presumidamente lésbicas que se ocuparam do tema - como é o caso de Cassandra Rios e Adelaide Carraro - é muito frequente que personagens trans sejam abordados como "estudos de caso" de personalidades patológicas, bizarras e aberrantes, vistas como a encarnação de transtornos médico-psiquiátricos ou como desvios que confirmam a regra cis/heteronormativa da gramática de subjetividades legítimas e legíveis. Cabe aqui retomar a pergunta feita por Schmidt em um contexto bastante distinto - o da representação das mulheres negras na ficção de autoria afro-estadunidense - mas que se torna igualmente produtiva: o que acontece quando o objeto da representação deixa de ser personagem e passa a ser sujeito da enunciação literária?

A partir da década de 1980 as vozes trans (travestis, transexuais, transgêneras e não binárias) começam a ganhar espaço no campo das narrativas literárias. Contudo, só muito recentemente a figura do escritor e da escritora trans emerge efetivamente no cenário literário. Pode-se mencionar, a título de exemplo, os livros A queda para o alto (1982), de Anderson Herzer (frequentemente citado como a primeira narrativa trans publicada no Brasil); Erro de pessoa: Joana ou João? (1985), Viagem solitária: memórias de um transexual trinta anos depois (2011) e Velhice transviada: memórias e reflexões (2019), de João W. Nery; Meu corpo, minha prisão: autobiografia de um transexual (1985), de Loris Ádreon; Olhares de Claudia Wonder: crônicas e outras histórias (2008); E se eu fosse puta (2016), de Amara Moira; Meu nome é Amanda (2016), de Amanda Guimarães (com a participação de Lielson Zeni) ${ }^{7}$; O sexo dos tubarões (2017), de Naná DeLuca; Vidas trans: a coragem de existir (2017), escrito a oito mãos - T. Brant, Amara Moira, João W. Nery e Márcia Rocha - ; e Contos transantropológicos (2018), de Atena Beauvoir. Gostaria de discutir com mais atenção a obra de João W. Nery e de Loris Ádreon.

\footnotetext{
7 Meu nome é Amanda configura-se como uma espécie de narrativa testemunho, escrita com a colaboração de Lienson Zeni. Amanda Guimarães, natural da região metropolitana de Porto Alegre, faz parte da geração de jovens que conquistou espaço na mídia com o fenômeno YouTube. Posteriormente, com o sucesso de seu canal de vídeos, publicou um livro, sem grandes pretensões literárias, cujo principal objetivo é contar o itinerário de sua transição de gênero.
} 
Antes disso, entretanto, comento brevemente dois textos bastante importantes e de interesse para o cenário da literatura trans brasileira que foram aqui deliberadamente deixados de lado. São duas narrativas-testemunho, escritas a quatro mãos que, apesar de muito pouco estudadas, encaixamse confortavelmente na genealogia do testemunho latino-americano. A primeira delas é Memórias de Madame Satã, narradas por João Francisco dos Santos (o próprio Madame Satã) ao jornalista Sylvan Paezzo e publicada em 1972; a outra é A Princesa: depoimentos de um travesti brasileiro a um líder das brigadas vermelhas, publicada em italiano em 1994 (traduzida para o português e publicada no Brasil em 1995), de autoria de Fernanda Farias de Albuquerque e de Maurizio Jannelli.

João W. Nery é provavelmente o autor trans mais profícuo da literatura brasileira. É autor de três narrativas memorialistas de cunho bastante autobiográfico, ademais de ter participado do livro coletivo Vidas trans: a coragem de existir (Bauru, Astral Cultural, 2017). Em 1977, em um Brasil ferido por um regime autoritário, João Nery submeteu-se a uma série de cirurgias clandestinas para realizar a redesignação sexual de seu corpo, e obtém uma série de documentos falsificados para ter sua identidade masculina reconhecida. Como consequência, perdeu o seu diploma universitário, já que cursara Psicologia da UFRJ com seu nome de batismo, feminino, em um período anterior à transição e às cirurgias. Junto com o diploma, perde também o seu mestrado (que se encontrava em andamento no período), e toda a clientela de seu consultório (já que atuava profissionalmente como uma mulher cissexual). Nery relembra de sua infância e de sua percepção de si como menino já na infância nas páginas de Erro de pessoa: Joana ou João?, publicado em 1985:

Ao completar oito anos, recebi uma boneca da tia que mais gostava.

- É pra você ninar e cuidar dela, como uma verdadeira mãezinha.

A festa acabou ali. Na hora de apagar as velinhas, como em muitos outros de meus aniversários, concentrei-me no mesmo pedido: "quero ser um menino com os outros". (NERY, 1985, p. 29)

Viagem solitária: memórias de um transexual trinta anos depois (2011) consiste em uma continuação, uma reelaboração e um aprofundamento de seu primeiro livro de memórias, de 1985. Viagem solitária recebeu dois importantes prêmios de Literatura: o Prêmio Astra (da Associação de Travestis e Transexuais do Rio de Janeiro, em 2011) e o prêmio da 10a Parada Gay de São Paulo, em 2012. Velhice transviada: memórias e reflexões (2019) foi publicado postumamente, quando João Nery enfrentava as complicações advinda de um câncer de pulmão que o levou à morte. Esse talvez seja o mais significativo dos livros do autor. Se, nos livros anteriores, o foco estava na infância, no processo de transição, na luta pela busca de reconhecimento civil de sua identidade transmasculina e de sua trajetória pelos direitos de gays, lésbicas e transexuais, em sua última narrativa, Nery concentra seu interesse principalmente sobre as idiossincrasias do processo de envelhecimento como um homem trans. Nery abre o livro fazendo uma referência ao filme que inspira o título de seu último livro:

Nasci na época certa, a da "juventude transviada". Eram os que se desviavam do rumo "normal". O filme dos "rebeldes sem causa", de 1955, foi aquele que retratou o jovem motoqueiro, de casaco de couro e cigarro no canto da boca como eu, carregando no peito um sentimento de impotência, de dúvidas e de falta de sentido neste mundo pré-formatado. Era uma geração que começava a querer um modelo alternativo de sociedade e que, pouco mais de uma década após o filme, faria acontecer o grande evento sociopolítico-cultural de maio de 1968 mundo afora. 
As dúvidas continuam na minha velhice transviada: se sou um transvelho [sic] vivendo em um novo mundo ou a releitura de um mundo velho, ou se sou um cara que reinventei meu velho mundo novo. Não tenho mais como acompanhar todas as novidades e digeri-las: a rapidez da robótica, da biotecnologia, dos programinhas para celular ou dos ritmos musicais. Tudo é mais lento e doído, da cabeça aos pés. (NERY, 2019, p. 15)

Apesar da notoriedade como autor e como pessoa pública alcançada por João W. Nery, é sintomático que muito pouco haja de produção bibliográfica tomando como objeto de análise seus livros e sua literatura. Por mais que se possa argumentar que o gênero literário escolhido por Nery - a autobiografia e o depoimento memorialista, quase testemunhal - não raro sejam vistos como gêneros literários menores ou de pouca monta pela crítica literária, o que mais incomoda é ver que o autor, mesmo após seu sucesso literário, continua sendo tornado objeto nos artigos que se dedicam direta ou indiretamente à sua produção literária. As narrativas por Nery publicadas deixam de ser tomadas como objetos de análise (seus aspectos formais, sua qualidade ou falta de qualidade, seu valor ou sua falta de valor), e a intenção recai quase que exclusivamente sobre o enredo e a materialidade da vida do autor, e não sobre o enredo ou a materialidade dos enredos literariamente trabalhados por João W. Nery na reorganização, a posteriori, de suas experiências vividas. Veja-se, como exemplo desse tratamento, o artigo de Guilherme Almeida (2012), publicado na revista Estudos Feministas, que reduz monumento a documento, tomando a produção de Nery quase que exclusivamente como fonte de dados biográficos do autor, sem se preocupar com a construção linguística e literária dessa produção.

No mesmo ano em que Nery publica seu primeiro volume de memórias, Loris Ádreon publica, pela editora Marco Zero, Meu corpo, minha prisão: autobiografia de um transexual. A narrativa situase temporalmente entre meados da década de 1960 e inícios da década de 1970. Loris, nessa obra, publicada três anos após a de Anderson/Sandra Herzer ${ }^{8}$, permitirá ao leitor uma outra aproximação com a experiência de trânsito identitário, embora ambas as narrativas se contextualizem no mesmo período - meados dos anos de 1960 e década de 1970. Loris, diferentemente de Herzer (internado na FEBEM após uma tentativa de abuso perpetrada por seu tio), é branca, oriunda de uma família nuclearmente estruturada e com recursos materiais. Isso coloca Loris em um outro patamar discursivo, marcado por uma localização na estratificação social brasileira bastante privilegiada, o que lhe permite, por exemplo, seu deslocamento até Manaus, onde completa seus estudos e têm acesso a leituras e informações acerca da sua condição de sexo/gênero, através de leituras sobre "casos como o seu", que lhe são facultadas a partir do acesso à biblioteca de um médico de família (CHAVES, 2018, sem paginação).

Ao longo do testemunho de Loris Ádreon, fica evidente a emersão de uma voz narrativa que busca uma verdade sobre si mesma, entendendo-se, dentro do enquadramento sistemático apresentado pelo script da maioria das narrativas trans (especialmente daquelas escritas por autores cisgênero) do "ter nascido no corpo errado". Todavia, ainda que Loris Ádreon se encontrasse em uma situação efetivamente privilegiada (se colocada em contraponto com a de outros autores de seu tempo, tais como Anderson Herzer), alguns dos tropos que aparecem no tecido textual de Meu corpo, minha prisão: autobiografia de um transexual são aqueles que marcam a trajetória da narradora/protagonista de maneira indelével,

8 Anderson é o nome escolhido por Herzer, que o utilizava simultaneamente ao seu apelido na FEBEM, "Bigode”. Sandra era o seu nome civil. Essa tensão entre os gêneros masculino e feminino não só é constitutiva do tecido textual de $A$ queda para o alto, como é mantida na própria edição impressa, que traz como registro de autoria apenas o sobrenome Herzer, omitindo tanto um quanto outro prenome. 
e que não raro se repetem na constituição do Leitmotiv das narrativas que tematizam trajetórias trans: as marcas da violência (tanto física quanto psicológica), bem como bullying homofóbico e transfóbico como faceta constitutiva do ambiente escolar, como Ádreon relata ao recuperar suas memórias escolares vividas em Manaus, na década de 1970:

Quando se iniciaram as aulas no meu último ano de ginásio, foi que as coisas se agravaram a um ponto insuportável para mim. [...] - "Veja, ele não tem pelos nas pernas! Olhe, as coxinhas dele como são redondas e macias, são como as de meninas! Escutem a fala dele! É fala de mulher! O bumbum dele não é de homem nem aqui, nem na China!" [...]. Uma vez, lembro-me, fui reclamar ao professor de português sobre um aluno que se sentava atrás de mim, pois cada vez que eu levantava para apanhar alguma coisa, [o aluno] passava a mão em meu traseiro. O professor olhou para a classe, depois para mim por sobre os óculos e disse: "é simples a solução para esse caso: casa-se com ele”. (ÁDREON, 1985, p. 59)

Diferentemente de Herzer, por ter nascido e sido criada no seio de uma família de classe média, Loris Ádreon pode desfrutar de uma certa estabilidade econômica que lhe permitiu tanto finalizar seus estudos quanto realizar sua cirurgia de redesignação sexual. A presença da família, entretanto, nem sempre foi positiva ao longo da trajetória de Ádreon, que ao longo da adolescência foi submetida a tratamento hormonal ${ }^{9}$ para que os traços caracteristicamente reconhecidos como masculinos aflorassem em seu corpo (LANZ, 2017, p. 403), o que ilustra, em sua biografia, o conhecido suplício a que jovens trans são submetidos - quase sempre à revelia da vontade desses jovens - na tentativa de "curar" a disforia de gênero:

Impelido pela dor e pelo ódio que fervia em meu coração, soltei um agudo grito, um tolo desabafo perante os demais, visto que não tinha outra forma de extravasar minha revolta. Prof. Normand apertou fortemente meu braço dizendo: - "Calma, calma menino, o mundo não vai se acabar por causa de uma injeçãozinha dessas, na vida existem coisas piores!” (ÁDREON, 1985, p. 54)

Esse episódio particular de Meu corpo, minha prisão: autobiografia de um transexual ilustra uma triste dinâmica social que aflige não apenas crianças e jovens transexuais, mas toda a comunidade LGBTQIA+: a violência doméstica que emana do seio da família nuclear heterossexual e de seus supostos valores morais vagamente judaico-cristãos. Se a família, por definição, é o espaço de carinho e proteção, tanto em termos afetivos quanto econômicos, para a maioria dos jovens, ela não raro se torna a torre panóptica ${ }^{10}$ de vigilância, controle e exercício de violência disciplinar sofrida pela comunidade LGBTQIA+ logo em seus primeiros anos de socialização. Torna-se bastante atrativa aqui a invocação da categoria homofobia familiar, desenvolvida por Sarah Schulman em Ties That Bind: Familial Homophobia and Its Consequences (2009), e sua respectiva realocação no campo mais específico da transfobia:

In order for us to come to a cultural agreement that homophobia within the family is wrong, we need one basic shared assumption: homophobia is not the fault of gay people. Homophobia is not caused by gay people. There is nothing that a gay person can ever do to justify it. Homophobia is a pathological manifestation of heterossexual culture. As a pure prejudice, it is wrong and as a social currency within and outside of the family, it is despicable. If a straight person does not like a gay person or is competing with a

9 Para Ádreon, esse episódio de violência familiar e tratamento médico arbitrário foi o responsável, inclusive, por uma tentativa de suicídio em sua juventude.

10 A utilização do panóptico para ilustrar o modus operandi da família nuclear heterossexual transfóbica em suas reiteradas investidas intervencionistas sobre o corpo de sujeitos transexuais foi tomada da discussão apresentada por Leocádia Aparecida Chaves (2018), que também discute a autobiografia de Loris Ádreon. 
gay person, whenever in the marketplace or in sibling rivalty, it is never appropriate to use homophobia as a leveler. (SCHULMAN, 2009, p. 23 - grifos meus) ${ }^{11}$

\section{CODA: PENSAR A LITERATURA TRANS}

No século XXI, é possível vislumbrar uma explosão editorial e um interesse crescente dos leitores pela literatura trans no Brasil, inclusive com o surgimento de coleções e editoras voltadas à questão, como é o caso da Padê Editorial. No cenário acadêmico, grupos de pesquisa consolidam-se e ganham visibilidade intra- e interinstitucional. As discussões sobre o pensamento e a literatura trans, entretanto, carecem de uma maior visibilidade no campo específico dos estudos literários. Uma das justificativas para a diluição do conhecimento produzido deve-se ao caráter marcadamente interdisciplinar da pesquisa em torno das questões trans, bem como em função das diferenças de alianças e estratégias epistêmicas adotadas pelos pesquisadores. Não raro, os pesquisadores do assunto afiliam-se a grupos feministas e/ou queers com amplas agendas de interesse, fazendo com que a especificidade dos estudos sobre literatura e cultura trans diluam-se no campo mais específico das teorias feministas, dos estudos de gênero e sexualidade e de grupos de pesquisa mais alinhados com investigações em torno de questões gays e lésbicas em outros campos disciplinares, tais como a psicologia, a comunicação, a educação e a história. Nesse sentido, pode-se pensar, por exemplo, em grandes eventos tradicionais no cenário intelectual brasileiro como o Fazendo Gênero ${ }^{12}$ e o Desfazendo Gênero ${ }^{13}$, em associações científicas como a ABEH (Associação Brasileira de Estudos da Homocultura) ${ }^{14}$, ou ainda em Grupos de Trabalho como o Homocultura e Linguagens (da Associação Nacional de Pós-Graduação e Pesquisa em Literatura e Linguística) ${ }^{15}$, o Filosofia e Gênero (da Associação Nacional de Pós-Graduação e Pesquisa em Filosofia - ANPOF) ${ }^{16}$, o Estudos de Gênero (da Associação Nacional de Pós-Graduação e Pesquisa em História - ANPUH) ${ }^{17}$, o Gênero, Sexualidade e Educação (da Associação Nacional de Pós-Graduação e Pesquisa em Educação - ANPED) ${ }^{18}$ e o Estéticas, Políticas do Corpo e Gêneros (da Sociedade Brasileira de Estudos Interdisciplinares da Comunicação INTERCOM $)^{19}$. Como se torna evidente nas próprias autodenominações desses eventos, associações e grupos de trabalho, a especificidade das questões, pautas e demandas da comunidade travesti, transexual e transgênero brasileira encontram-se subsumidas, rasuradas e/ou eclipsadas por termos tais como homocultura, gênero, corpo e sexualidade. Não é necessária uma grande perspicácia para compreender os riscos e consequências - em termos epistêmicos - desse tipo de apagamento.

\footnotetext{
11 O capítulo inicial do livro encontra-se traduzido por Felipe Bruno Martins Fernandes como "Homofobia familiar: uma experiência em busca de reconhecimento", publicado no número 5 (2010) da revista Bagoas.

$12 \mathrm{O}$ histórico das edições do evento, que sempre é sediado na Universidade Federal de Santa Catarina, sob os auspícios do Instituto de Estudos de Gênero, pode ser consultado em: <http://www.fazendogenero.eventos.dype.com.br/>. Acesso em: 21 de abril de 2001.

13 Evento itinerante, via de regra realizado a cada dois anos em uma universidade federal da região nordeste do Brasil. O website da última edição do evento pode ser consultado em <https://desfazendogenero.com.br/sobre.php>. Acesso em: 21 de abril de 2021.

14 A associação realiza um evento itinerante a cada dois anos, o CINABEH (Congresso Internacional de Estudos da Homocultura), via de regra sediado em uma universidade federal. O website da ABEH pode ser consultado em: <http://www.abeh.net.br/>. Acesso em: 21 de abril de 2021.

15 Cf. <https://anpoll.org.br/gt/homocultura-e-linguagens/>. Acesso em: 21 de abril de 2021.

16 Cf. <https://anpof.org.br/gt/gt-filosofia-e-genero $>$. Acesso em: 21 de abril de 2021.

17 Cf. <https://anpuh.org.br/index.php/grupos-de-trabalho-rj/gt-de-estudos-de-genero>. Acesso em: 21 de abril de 2021.

18 Cf. <https://anped.org.br/grupos-de-trabalho/gt23-g\%C3\%AAnero-sexualidade-e-educa\%C3\%A7\%C3\%A3o >. Acesso em: 21 de abril de 2021.

19 Cf. <https://www.portalintercom.org.br/index.php?/eventos1/gps1/gp-esteticas-politicas-do-corpo-e-generos>. Acesso em: 21 de abril de 2021.
} 
Cabe um último questionamento acerca do tipo de script narrativo que é construído ao longo das narrativas trans. Pesquisadores tais como Aren Z. Aizura (2018), que se ocuparam com o estudo de narrativas em um contexto transnacional, destacam a recorrência de uma estrutura narrativa quase normativa que emerge desse universo textual. Via de regra, o fio condutor dessas histórias emerge marcado por uma busca de adequação ao universo imaginário cisnormativo, com a busca da adequação da materialidade corporal do sujeito às expectativas de gênero de um potencial público leitor. Isso fica visível quando se observam os tropos recorrentes, tais como os de "personagem preso no corpo errado", "homem com alma de mulher" (ou "mulher com alma de homem"), bem como a ênfase na cirurgia de redesignação sexual (faloplastia ou vaginoplastia) e o "renascimento para uma nova identidade" (o que continua legitimando o status quo de vivências mais ou menos legítimas para pessoas trans). Esses tropos, quando organizados ao longo de uma lógica narrativa que privilegia uma sequência linear de [vida passada no corpo errado $]+$ [descoberta da condição transexual $]+[$ transição para o sexo/gênero oposto $]+[$ novo corpo / estabilidade emocional / "final feliz"], constroem uma sequência narrativa quase canônica, especialmente nas narrativas de autores cissexuais que tematizam as experiências transexuais/transgêneros, e que, como consequência, pasteuriza e edulcora a singularidade de diferentes personagens trans, criando a ilusão de uma identidade e de uma trajetória homogêneas, mesmo no que diz respeito aos percalços enfrentados para a construção de vivências, existências e experiências de transexuais, travestis e transgêneros, seja no mundo da ficção, seja na realidade real (e aqui o pleonasmo faz-se necessário). Felizmente, as vozes trans estão deixando de ser meros objetos da representação literária, e passam a invadir, ocupar e reivindicar o espaço autoral de produção de capital simbólico no campo da literatura brasileira, registrando, construindo e desconstruindo suas próprias trajetórias. Em sendo assim, finalizo com os versos de Linn da Quebrada, que corroboram essa afirmação:

\author{
Estou procurando, estou tentado entender \\ O que é que tem em mim \\ Que tanto incomoda você \\ Se é a sobrancelha, o peito \\ A barba, o quadril sujeito \\ O joelho ralado, apoiado no azulejo \\ Que deixa na boca o gosto, o beiço \\ Saliva, desejo \\ Seguem passos certos \\ Escritos em linhas tortas \\ Dentro de armários suados \\ No cio de seu desespero ${ }^{20}$.
}

20 DA QUEBRADA, Linn. Submissa do 7o dia. In: DA QUEBRADA, Linn. Pajubá, 2017. Letra disponível em: <https://www.letras.mus.br/ mc-linn-da-quebrada/submissa-do-7-dia/>; faixa de áudio do EP disponível em <https://youtu.be/Kfhie6Y5Qc>. Links acessados em: 16 de abril de 2021. 


\section{REFERÊNCIAS}

ABREU, Caio Fernando. Sargento Garcia. In: ABREU, Caio Fernando. Morangos mofados. São Paulo: Brasiliense, 1982. p. 71-86.

ABREU, Caio Fernando. Dama da noite. In: ABREU, Caio Fernando. Os dragões não conhecem o paraíso. São Paulo: Companhia das Letras, 1988. p. 83-90.

ÁDREON, Loris. Meu corpo, minha prisão: autobiografia de um transexual. Rio de Janeiro: Marco Zero, 1985.

AIZURA, Aren Z. Mobile Subjects: Transnational Imaginaries of Gender Reassignment. London: Duke University Press Books, 2018.

ALBUQUERQUE, Fernanda Farias de; JANNELLI, Maurizio. Princesa. Roma: Sensibili alle Foglie, 1994.

ALBUQUERQUE, Fernanda Farias de; JANNELLI, Maurizio. A Princesa: depoimentos de um travesti brasileiro a um líder das Brigadas Vermelhas. Trad. Elisa Byngton. Rio de Janeiro: Nova Fronteira, 1995.

ALMEIDA, Guilherme. 'Homens trans': novos matizes na aquarela das masculinidades? Estudos Feministas (Florianópolis), n. 20, v. 2, p. 513-523, maio-agosto/2012.

ALÓS, Anselmo Peres. O corpo disciplinado: uma leitura de "Sargento Garcia” (1982), de Caio Fernando Abreu. Conexão Letras, Porto Alegre, v. 14, n. 21, p. 99-111, jan.-jun. 2019. Disponível em: https://seer.ufrgs. br/conexaoletras/article/view/94343/53234. Acesso em: 12 de abril de 2021.

ALÓS, Anselmo Peres. Traduzir o queer: uma opção viável? Revista Estudos Feministas. Florianópolis (UFSC), 2020, vol. 28, n. 2, e60099. Disponível em: http://dx.doi.org/10.1590/1806-9584-2020v28n260099. Acesso em: 16 de abril de 2020.

AMERICAN PSYCHIATRIC ASSOCIATION. Manual Diagnóstico e Estatístico de Transtornos Mentais (DSM-IV 1994). Trad. Cláudia Dorneles. 4. ed. Porto Alegre: Artmed, 2002.

AMERICAN PSYCHIATRIC ASSOCIATION. Manual diagnóstico e estatístico de transtornos mentais (DSM-V 2013) [recurso eletrônico]. Trad. Maria Inês Corrêa Nascimento et al. Revisão técnica de Aristides Volpato Cordioli et al. 5. ed. Dados eletrônicos. Porto Alegre: Artmed, 2014. Disponível em: http://www.niip.com. br/wp-content/uploads/2018/06/Manual-Diagnosico-e-Estatistico-de-Transtornos-Mentais-DSM-5-1pdf.pdf. Acesso em: 01 de abril de 2021.

ANGRIMANI, Danilo. Nicola: um romance transgênero. São Paulo: Summus, 1999.

AYALA, Walmir. Taís [1966]. In: DAMATA, Gasparino (Org.). Histórias do amor maldito. Rio de Janeiro: Record, 1967, p. 253-268.

BEAUVOIR, Atena. Contos transantropológicos. Porto Alegre: Taverna, 2018.

BENEDETTI, Marcos Renato. Toda feita: o corpo e o gênero das travestis. Rio de Janeiro: Garamond, 2005.

BENTO, Berenice. A (re)invenção do corpo: sexualidade e gênero na experiência transexual. Rio de Janeiro: Garamond, 2006.

BORBA, Rodrigo. $O$ (des)aprendizado de si: transexualidades, interação e cuidado em saúde. Rio de Janeiro: Fiocruz, 2016.

BORNSTEIN, K. Gender Outlaw: Men, Women and the Rest of Us. New York: Routledge, 1994.

BRANT, T.; MOIRA, Amara; NERY, João W.; ROCHA, Márcia. Vidas trans: a coragem de existir. Bauru: Astral Cultural, 2017.

BRASIL. Resolução $n^{\circ} 1.955$, de 3 de setembro de 2010. Dispõe sobre a cirurgia de transgenitalismo e revoga a Resolução CFM no 1.652, de 2 de dezembro de 2002. Diário Oficial da União, 3 de setembro de 2010. 
BRASIL. Portaria $n^{\circ}$ 2.803/GM, de 19 de novembro de 2013. Redefine e amplia o Processo Transexualizador no Sistema Único de Saúde (SUS). Diário Oficial da União, 19 de novembro de 2013.

CARDOSO, Lúcio. Crônica da casa assassinada. 3. ed. Edição crítica coordenada por Mario Carelli. Nanterre/ São Paulo: ALLCA XX/Scipione Cultural, 1997.

CARRARO, Adelaide. O travesti. São Paulo: Loren, 1970.

CHAVES, Leocádia Aparecida. Autobiografias trans em contexto de ditadura: a coragem de dizer. GELBCUNB. BLOGSPOT. Brasília, 03 de junho de 2018. Disponível em: <https://gelbcunb.blogspot.com/2018/06/>. Acesso em: 19 de abril de 2021.

DA QUEBRADA, Linn. Mulher. In: DA QUEBRADA, Linn. Pajubá, 2017. Letra disponível em https:// www.letras.mus.br/mc-linn-da-quebrada/mulher/; faixa de áudio do EP disponível em https://youtu.be/ V8UxhqxA_Ms?list=OLAK5uy_nobNtjQAXSCTQpSYINbJLGU2Qc2vHz_5w. Links acessados em: 16 de abril de $\overline{2021 .}$

DA QUEBRADA, Linn. Submissa do 7o dia. In: DA QUEBRADA, Linn. Pajubá, 2017. Letra disponível em: https://www.letras.mus.br/mc-linn-da-quebrada/submissa-do-7-dia/; faixa de áudio do EP disponível em https://youtu.be/Kfjhie6Y5Qc. Links acessados em: 16 de abril de 2021.

DELUCA, Naná. O sexo dos tubarões. São Paulo: Patuá, 2017.

FONSECA, Rubem (1975). Dia dos namorados. In: RUFFATO, Luiz (Org.). Entre nós. Rio de Janeiro: Língua Geral, 2007, p. 125-136.

FREIRE, Roberto. Travesti. São Paulo: Símbolo, 1978.

GUIMARÃES, Amanda (com Lielson Zeni). Meu nome é Amanda. Rio de Janeiro: Fábrica321 / Rocco, 2016.

HALBERSTAM, J. Female Masculinity. Durham, NC: Duke University Press, 1998.

HALBERSTAM, J. In a Queer Time and Space: Transgender Bodies, Subcultural Lives. New York and London: New York University Press, 2005.

HERZER, Anderson. A queda para o alto. Petrópolis: Vozes, 1982.

HEUSER, Paulo. A rua. Crônicas do Heuser, 06/12/2006. Disponível em: http://pauloheuser.blogspot. com/2006/12/rua.html. Acesso em: 02 de setembro de 2018.

HINES, Sally. TransForming Gender: Transgender Practices of Identity, Intimacy and Care. Bristol: Policy Press, 2007.

LANZ, Letícia. O corpo da roupa: a pessoa transgênera entre a transgressão e a conformidade com as normas de gênero. 2. ed. Curitiba: Movimento Transgente, 2017.

LARANGEIRA, Álvaro N. A dignidade da literatura: Adelaide Carraro e a subversão ao regime militar. Lumina, v. 10, n. 1, p. 1-13, 2016. Disponível em: <https://periodicos.uff.br/index.php/lumina/ article/view/21186>. Acesso em: 16 de abril de 2021.

MAGALHÃES JÚNIOR, R. A grande atração. In: DAMATA, G. (Org.). Histórias do amor maldito. Rio de Janeiro: Record, 1967, p. 202-211.

MARTINS, Julio César Monteiro. Sabe quem dançou? Rio de Janeiro: Codecri, 1978.

MARTINS, Julio César Monteiro (1978). Ruiva. In: RUFFATO, Luiz. (Org.) Entre nós. Rio de Janeiro: Língua Geral, 2007, p. 241-256.

MOIRA, Amara. E se eu fosse puta. São Paulo: Hoo, 2016. 
NERY, João W. Erro de pessoa: Joana ou João? Rio de Janeiro: Record, 1985.

NERY, João W. Viagem solitária: memórias de um transexual trinta anos depois. São Paulo: Leya, 2011.

NERY, João W. Velhice transviada: memórias e reflexões. Rio de Janeiro: Objetiva, 2019.

PROSSER, J. Second Skins: The Body Narratives of Transsexuality. New York: Columbia University Press, 1998.

REIMAO, Sandra. "Proíbo a publicação e circulação...”: censura a livros na ditadura militar. Estudos avançados. São Paulo, v. 28, n. 80, p. 75-90, abril de 2014. Disponível em: <http://dx.doi.org/10.1590/S0103$40142014000100008>$. Acesso em: 16 de abril de 2021.

RIOS, Cassandra. Georgette. São Paulo: Record, 1956.

RIOS, Cassandra (1965). Uma mulher diferente. São Paulo: Brasiliense, 2005.

ROCON, Pablo Cardozo. Quando os corpos trans adentram o processo transexualizador: experiências que conformam a transexualidade. Dissertação de Mestrado. Universidade Federal do Espírito Santo, Vitória, 2018.

ROCON, Pablo Cardozo; RODRIGUES, A.; ZAMBONI, J.; PEDRINI, M. D. Dificuldades vividas por pessoas trans no acesso ao Sistema Único de Saúde. Ciência e Saúde Coletiva, n. 21, v. 8, p. 2517-2525, 2016.

ROSA, João Guimarães (1956). Grande Sertão: Veredas. Rio de Janeiro: Nova Fronteira, 2001.

SANTOS, João Francisco dos; PAEZZO, Sylvan. Memórias de Madame Satã. Rio de Janeiro: Lidador, 1972.

SCHMIDT, Rita Terezinha. Em busca da história não contada ou: o que acontece quando o objeto começa a falar. Letras, Santa Maria, v. 16, p. 183-196, 1999.

SCHULMAN, Sarah. Ties That Bind: Familial Homophobia and Its Consequences. New York: The New Press, 2009.

SCHULMAN, Sarah. Homofobia familiar: uma experiência em busca de reconhecimento. Trad. Felipe Bruno Martins Fernandes. Bagoas, n. 5, p. 67-78, 2010. Disponível em: https://cchla.ufrn.br/bagoas/v04n05art04 schulman.pdf. Acesso em: 21 de abril de 2010.

SERRAN, Leopoldo. Shirley: a história de um travesti. Rio de Janeiro: Codecri, 1979.

WONDER, Claudia. Olhares de Claudia Wonder: crônicas e outras histórias. São Paulo: GLS Edições, 2008. 